\title{
Hysteretic Behavior of Twin Boundary Peak Due to Precipitation in Co-Ni-Cr alloy
}

\author{
Raffaele Cosimati ${ }^{a}{ }^{*}$, Daniele Mari ${ }^{a}(\mathbb{D})$ \\ ${ }^{a}$ École Polytechnique Fédérale de Lausanne, Institute Of Physics - IPHYS, Station 3, CH-1015 \\ Lausanne, Switzerland
}

Received: September 30, 2017; Revised: April 05, 2018; Accepted: May 16, 2018

\begin{abstract}
Anelastic behavior and microstructural changes of a Co-Ni-Cr super-alloy were monitored over the temperature range $250-950^{\circ} \mathrm{C}$, by using several complementary techniques. Two grades of this alloy were used, differing by the presence of small quantity of beryllium $(<1.5 \%$ at.). Thermoelectric power reveals two distinct precipitation stages. The first precipitation ("A"), common to both the grades, and a second one ("B"), occurring solely in the beryllium-containing alloy. Cold-worked alloys exhibit a transient large mechanical loss peak, associated to the recrystallization of the deformed materials, and two relaxation peaks situated at around $600^{\circ} \mathrm{C}$ (P1) and $780^{\circ} \mathrm{C}(\mathrm{P} 2)$. Instead, only the peak P1 occurs on the fully recrystallized material. $\mathrm{P} 1$ and $\mathrm{P} 2$ can be associated to the diffusion process involved in the first precipitation stage ("A") and to the twin boundary motion, respectively. The precipitation-dissolution process of precipitates "B", localized on the twin boundary, provides a hysteretic behavior of the peak P2.
\end{abstract}

Keywords: Internal friction, twin relaxation, NiBe, precipitation, super alloy.

\section{Introduction}

The outstanding properties of Cobalt-Nickel based alloys allow their application in a wide range of domains requiring huge mechanical strength combined with high corrosion and wear-resistance ${ }^{1,2}$.

To investigate the influence of minor elements added to the base composition on the anelastic behavior of a Co-Ni-Cr base alloy, two grades of a same alloy are used, differing by the presence of a small quantity of beryllium $(<1.5 \%$ at. $)$ in one of them.

Beryllium is largely used as alloying element in $\mathrm{Cu}-\mathrm{Be}$ alloys to make components, which are inert, stable, and do not give off emissions during use. However, some commercial $\mathrm{Ni}-\mathrm{Cr}$ alloy dental prosthesis include beryllium in their composition to improve the castability and the interaction with dental ceramics ${ }^{3-5}$.

Even if the investigated alloy is used with satisfaction since several years, the origin of its outstanding mechanical properties is still poorly understood, as well as the role of small alloying elements additions on mechanical properties. In absence of a literature on these alloys, this work brings a contribution in understanding the origin of the performance of this material, which will help the optimization of the treatment needed to achieve the desired properties.

Previous investigations on the same alloys showed that thermal treatments at a temperature between $550^{\circ} \mathrm{C}$ and $600^{\circ} \mathrm{C}$ produced a precipitation responsible for a remarkable hardening by pinning dislocations ${ }^{6,7}$.

In this paper, we show that the presence of NiBe precipitates in the beryllium-containing alloy ${ }^{8}$ produces a hysteresis on the mechanical loss spectrum linked to the movement of twins?.

The interpretation of mechanical spectroscopy measurements, based on a solution precipitation phenomenon, is supported by complementary techniques, such as thermoelectric power (TEP) and transmission electron microscopy (TEM).

\section{Experimental Procedures and Materials}

Two grades of a same Co-Ni-Cr based alloy were examined, differing by the presence of a small amount of $\mathrm{Be}(<1.5 \%$ at.). Alloy composition and concentration ranges are listed in Table 1 for both the grades (hereafter referred as "without Be" and "with Be").

The starting materials were received as cold-drawn rods with a diameter of $1.85 \mathrm{~mm}$. At this stage, the grains are elongated in the drawing direction with an average length of $30 \mu \mathrm{m}$ and an aspect ratio of five.

To get under control the initial microstructural state, the as received materials were annealed at $1200^{\circ} \mathrm{C}$ during 5 minutes under argon flow, and then rapidly cooled by

Table 1. Chemical composition and concentration range for the two grades of the examined Co-Ni-Cr based alloy.

\begin{tabular}{lcccccccc}
\hline Elements & $\mathrm{Co}$ & $\mathrm{Ni}$ & $\mathrm{Cr}$ & $\mathrm{Fe}$ & $\mathrm{W}$ & $\mathrm{Mo}$ & $\mathrm{Ti}$ & $\mathrm{Be}$ \\
\hline Without & $45-50 \%$ & $20-25 \%$ & $15-20 \%$ & $1-5 \%$ & $1-5 \%$ & $1-5 \%$ & $1-5 \%$ & $0 \%$ \\
With & $45-50 \%$ & $20-25 \%$ & $15-20 \%$ & $1-5 \%$ & $1-5 \%$ & $1-5 \%$ & $1-5 \%$ & $<1.5 \%$ \\
\hline
\end{tabular}


quenching in water. Such a treatment allows homogenizing the microstructure and saturating the solid solution, with a fully recrystallized structure free of any texture.

Cold-worked samples (CW) were produced by roll milling the solution treated rods with $50 \%$ reduction of the cross section. The width and thickness of the laminated CW samples were $3.35 \mathrm{~mm}$ and $0.4 \mathrm{~mm}$ respectively. The non-CW samples were not considered in the paper because they do not show the twin boundary peak, which is the main topic of the paper.

\section{Mechanical Spectroscopy}

Mechanical Spectroscopy allows to investigate, in a non-destructive way, the mobility of defects in materials ${ }^{10-12}$. Mechanical loss and dynamic shear modulus were measured by means of a forced inverted torsion pendulum ${ }^{13}$.

A periodic strain with constant amplitude of $5 \times 10^{-5}$ was applied on the sample, as long as temperature dependent internal friction measurements were carried out at a rate of $0.5 \mathrm{C} / \mathrm{min}$ for different frequencies ranging from $0.001 \mathrm{~Hz}$ to $1 \mathrm{~Hz}$. Heating and cooling cycles were separated by an isothermal annealing of 30 minutes.

Further measurements were accomplished at different strain amplitudes, to check the dependence of the mechanical loss spectra on the applied strain.

Internal friction peaks related to anelastic phenomena were fitted by an analytic expression obtained from the convolution of a Debye peak with a log-normal distribution of relaxation times around a mean value ${ }^{14,15}$ :

$$
\tan \phi=\frac{\Delta}{2 \sqrt{1+\Delta}} \sqrt{\pi \beta} \cdot \int_{-\infty}^{\infty} \frac{e^{-\frac{x^{2}}{\beta^{2}}}}{\cosh (\ln (\omega \tau))+x} d x
$$

The parameter $\beta$ quantifies the broadening of the peak. To consider the superimposition of these peaks on an exponential background ${ }^{16}$, internal friction peaks were extracted by subtraction of a fitted exponential high-temperature background given by ${ }^{15,17,18}$ :

$$
Q^{-1}=\frac{K}{(2 \pi f)^{n}} \cdot \exp \left(-\frac{n H_{b g}}{k_{b} T}\right)
$$

where $n$ is the characteristic exponent for the background, $K$ is a constant, and $H_{\mathrm{bg}}$ is an average activation energy for the background.

\section{Thermoelectric Power}

Seebeck coefficient of metallic materials is strongly sensitive to the amount of solute atoms ${ }^{19-21}$. Therefore, thermoelectric power (TEP) can be used to evaluate microstructural changes of the alloy taking place during various phase transformations at different annealing temperatures, such as precipitation.

The experimental apparatus is described in detail elsewhere ${ }^{7,13}$. The sample is fixed at each end to the copper reference blocks maintained at temperatures $10^{\circ} \mathrm{C}$ and $30^{\circ} \mathrm{C}$.
Each measurement requires about two minutes to obtain a stationary temperature profile within the sample.

Samples from both the grades were progressively heated at increasing temperatures, ranging from $250^{\circ} \mathrm{C}$ to $900^{\circ} \mathrm{C}$ : after annealing during 2 hours in a pre-heated furnace at a certain temperature, samples were water quenched. The TEP was recorded at room temperature after each annealing.

\section{Transmission Electron Microscopy}

After being measured in the pendulum, samples were analyzed by using aberration corrected HR-STEM and HRSTEM based EDS in a double aberration corrected FEI Titan Themis operating at $300 \mathrm{kV}$.

From the flat samples measured in the pendulum, 3-mm discs were cut by using a disc punch system. The discs were then mechanically polished to about $120 \mu \mathrm{m}$ thickness, before being processed by twin-jet electropolishing technique with a $10 \%$ perchloric acid - methanol solution, cooled to $-20^{\circ} \mathrm{C}$ with an applied potential of $20 \mathrm{~V}$. The edges near the etched perforation provided large electron transparency areas having a foil thickness between 5-25 $\mathrm{nm}$.

\section{Results and Discussion}

Mechanical loss spectra recorded during the first heating following the cold rolling are shown in Fig. 1 for both the grades of the alloy.

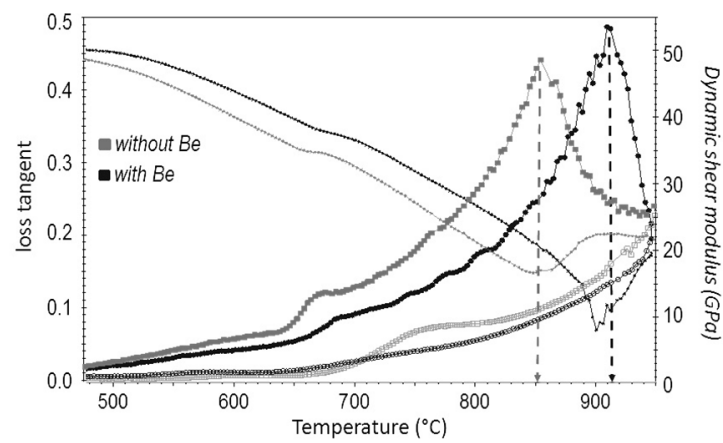

Figure 1. Mechanical loss and dynamic shear modulus measured during the first heating after cold rolling and the subsequent cooling, for CW samples without beryllium (grey) and with beryllium (black)

We remark that a sharp peak $\left(\mathrm{P}_{\mathrm{R}}\right)$, which coincides with a dip of the dynamic modulus, occurs at around $860^{\circ} \mathrm{C}$ for the alloy without $\mathrm{Be}$ and close to $910^{\circ} \mathrm{C}$ for the grade with Be. Since the peak $P_{R}$ only occurs on the first heating after the cold rolling, it can be associated with a transition from high IF background in deformed material to low IF background in annealed one due to recrystallization ${ }^{22}$. Indeed, on the following first cooling and over all the subsequent temperature scans, neither the peak $\mathrm{P}_{\mathrm{R}}$ nor the anomaly of the modulus were detected. This hypothesis is supported by 
hardness tests as a function of the annealing temperature (not shown here), showing a drop of hardness at the same temperatures as the recrystallization peaks.

As shown in Fig. 2, the general aspect of the mechanical loss spectra recorded on $\mathrm{CW}$ samples after several heating and cooling cycles reveals three characteristic components for both the grades of the alloy: a first relaxation peak at around $600^{\circ} \mathrm{C}(\mathrm{P} 1)$, a second relaxation peak occurring at around $800^{\circ} \mathrm{C}(\mathrm{P} 2)$, and an exponential high-temperature background.
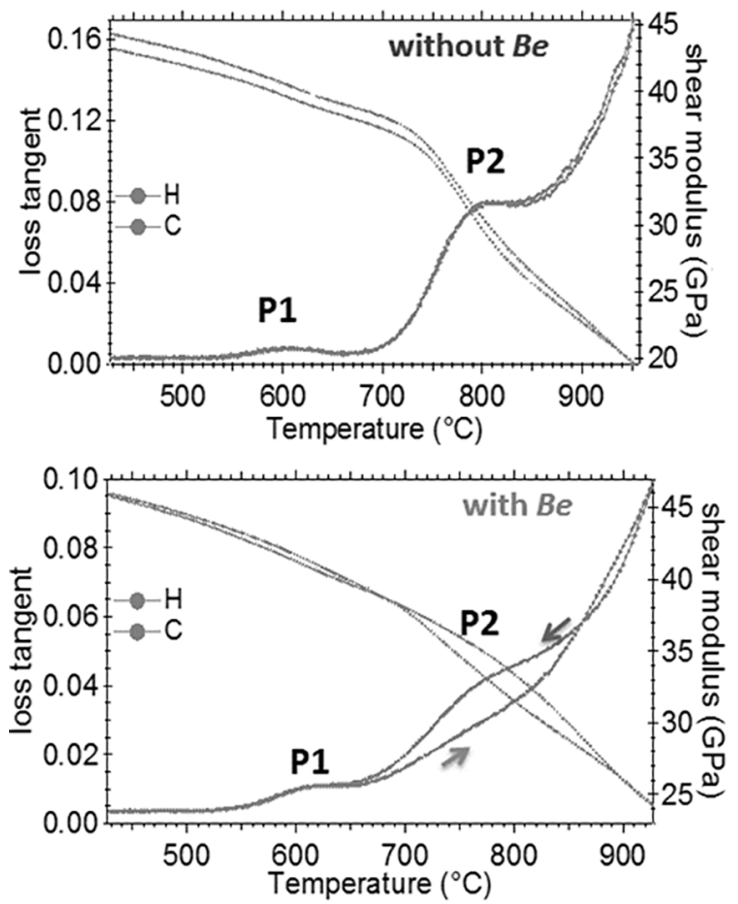

Figure 2. IF spectra for the alloy "without $\mathrm{Be}$ " and "with $\mathrm{Be}$ " in the CW state after several heating and cooling cycles. P1 and P2 can be associated to the diffusion process and to the twin boundary motion, respectively

These characteristic spectra were also obtained during scans at different frequencies, with a slight shift of temperature peaks due to thermal activation. The presence of both the peak P1 and $\mathrm{P} 2$ on isothermal internal friction spectra, measured as a function of frequency, confirms the thermally activated character of the peaks. Data processing allowed to decompose the spectrum into its components, i.e. the two relaxation peaks and the high-temperature exponential background with the respective parameters. Internal friction curves were fitted by using the equations (1) and (2), describing a Debye peak and the exponential rise of mechanical loss at high temperature, respectively.

Concerning the peak $\mathrm{P} 1$, occurring at around $600^{\circ} \mathrm{C}$, the Arzrhenius plot provided an activation energy $\mathrm{H}_{\text {act }} \sim 2.7 \mathrm{eV}$, with a limit relaxation time $\tau_{0} \sim 1.1 \cdot 10^{-15} \mathrm{~s}$. In both the grades, P1 is stable between heating and cooling, and rather symmetrical with a broadening factor $\beta \sim 1$. Moreover, the amplitude of the peak $\mathrm{P} 1$ does not depend on the amplitude of the applied stress.
The features described above suggest that $\mathrm{P} 1$ is a point defect peak. It could be associated with the diffusion of the atoms involved in a precipitation process occurring in the same temperature range, such as nickel and titanium. Indeed, we find in the literature that the diffusion energy of nickel ${ }^{23}$, in cobalt is between 2.6 and $3.1 \mathrm{eV}$, while that of titanium $^{23}$ in cobalt is between 2.0 and $2.9 \mathrm{eV}$, therefore reasonably close to the values obtained for the activation energy of the peak $\mathrm{P} 1$.

Thermoelectric power measurements support the interpretation of mechanical loss spectra.

As evidenced in Fig. 3, a broad maximum placed between $550^{\circ} \mathrm{C}$ and $600^{\circ} \mathrm{C}$ characterizes the TEP curves of both the alloys "without" and "with" beryllium. Former experiments carried out on the same material allowed to relate this maximum on TEP to a precipitation process occurring up to $600^{\circ} \mathrm{C}$, followed by dissolution of such precipitates (hereafter referred as "A") ${ }^{6,7}$.

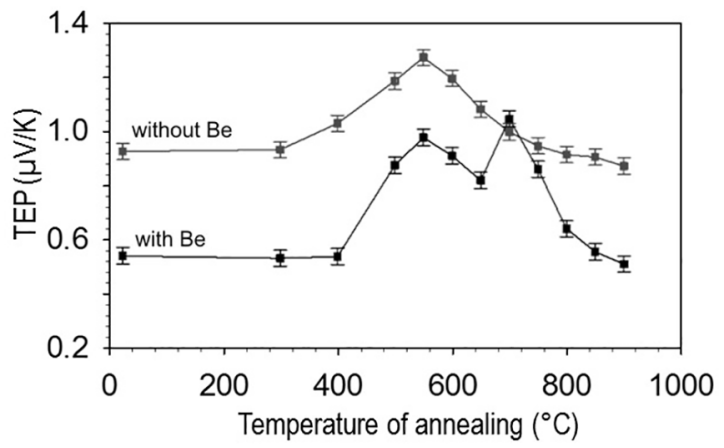

Figure 3. TEP as a function of annealing temperature for the alloy "without" (grey) and "with" (black) beryllium

However, TEP also reveals that a second precipitation (hereafter called "B") occurs solely in the berylliumcontaining alloy, by annealing at $700^{\circ} \mathrm{C}$. The BF TEM micrograph on Fig. 4a confirms the absence of precipitates on the twin boundaries in the alloy without beryllium, while Ni-rich particles were found on the boundaries of beryllium containing alloy (Fig. 4b) annealed at $700^{\circ} \mathrm{C}$.

As stated above, the samples that were not coldworked are not considered in the paper because they do not show the twin boundary peak, which is the main topic here. Indeed, after solution treatment, the microstructure appears free of texture, including twins. However, both $\mathrm{CW}$ and not-CW samples show the same TEP curves ${ }^{6,7}$, revealing the same precipitation stages.

Transmission electron microscopy investigations, involving HR-STEM EDS, allowed recognizing "B" precipitates formed at $700^{\circ} \mathrm{C}$ as $\mathrm{NiBe}$ intermetallic phase having a b.c.c. structure in a f.c.c. matrix ${ }^{8}$. For the peak P2, which occurs close to $800^{\circ} \mathrm{C}$, we get an apparent activation energy $\mathrm{H}_{\text {act }}>4.0 \mathrm{eV}$, due to a limit relaxation time $\tau_{0}<<1 \cdot 10^{-20} \mathrm{~s}$ (see Arrhenius plots in Fig. 4), and a broadening factor $\beta \sim 4.5$. 
Moreover, the amplitude of $\mathrm{P} 2$ depends on the amplitude of the applied stress. These features limit the possible relaxation mechanisms to phenomena involving a change in the structure of the material, like sliding or migration of grain or twin boundaries ${ }^{18}$.

The BF TEM image in Fig. 5a. shows that the twin boundaries of the alloy "without" beryllium are free from precipitates. On the contrary, EDX map in Fig. $4 b$ reveals the presence of nickel-rich precipitates having the same structure as "B" precipitates, on the twin boundaries of the beryllium-containing alloy. Even if the two maps in Fig. 4a,b refer to two different areas of two different samples, further investigations, not shown in the paper, do not reveal any significant differences in grain size.

Therefore, the hysteretic behavior of the peak P2 can be associated to the precipitation-dissolution process of "B" precipitates located on the twin boundaries.

The hysteresis of $\mathrm{P} 2$ between heating and cooling is explained as follow: the formation of "B" precipitates hinders the twin boundary migration and the relaxation peak $\mathrm{P} 2$. Their dissolution, occurring by annealing at higher temperature, allows the twin migration that possibly gives rise to the $\mathrm{P} 2$ peak over
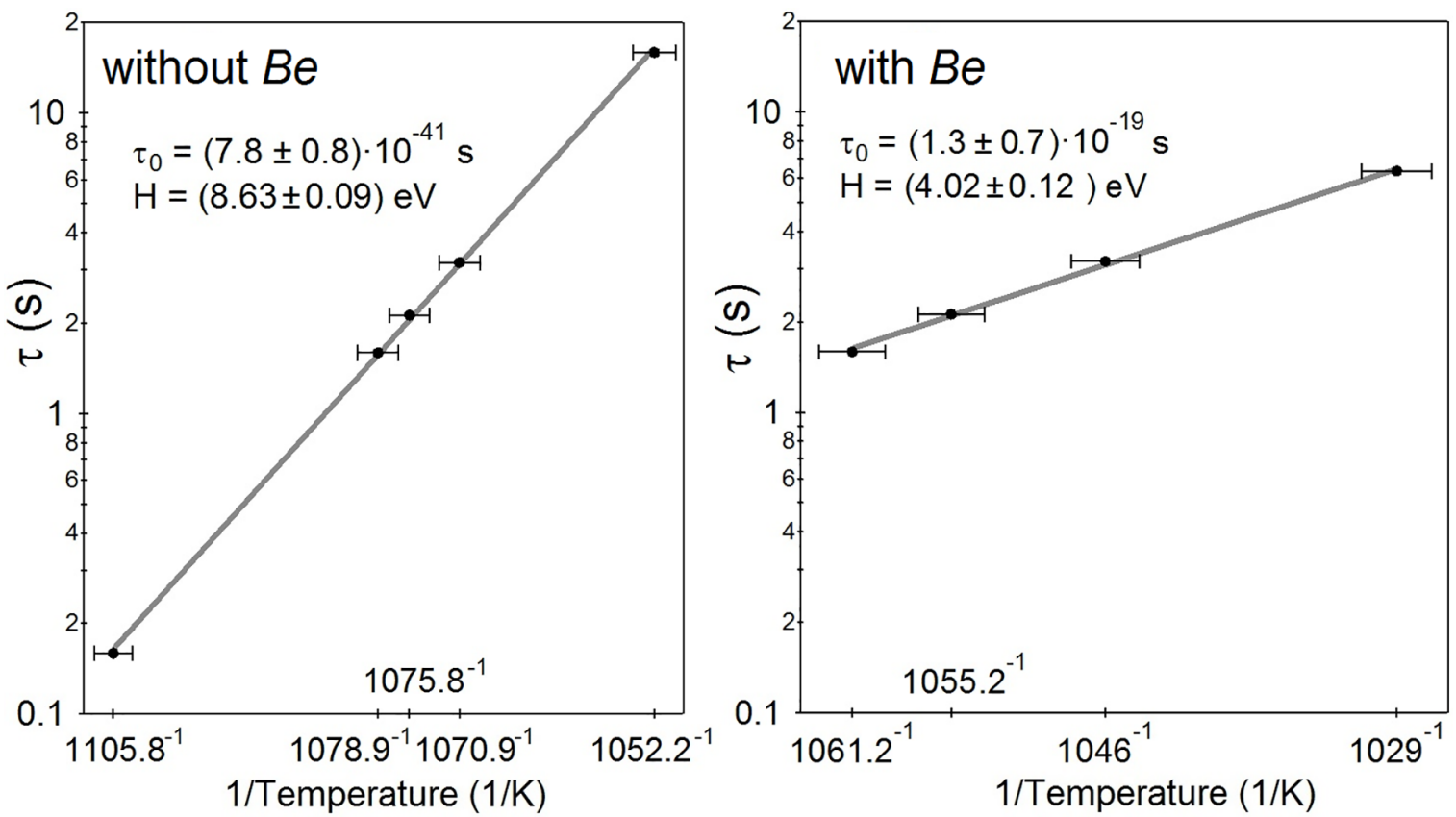

Figure 4. Arrhenius plot obtained for peak P2 provides an apparent activation energy due to a limit relaxation time $\tau_{0}<<1 \cdot 10^{-20} \mathrm{~s}$
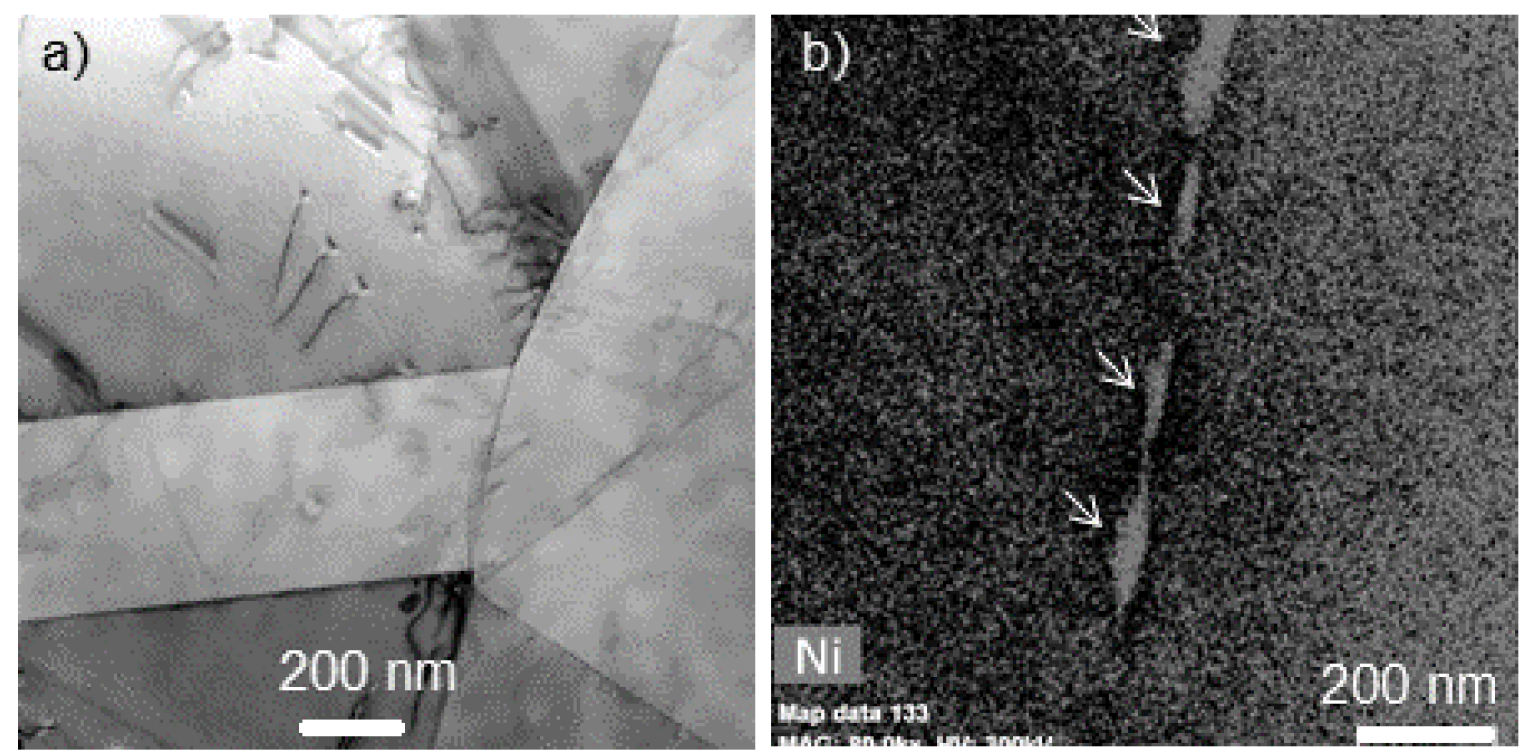

Figure 5. a) Absence of precipitates on twin boundaries in the alloy "without" beryllium. b) EDX map revealing nickel-rich precipitates, having the same structure as B precipitates, on the twin boundaries of the variant "with" beryllium 
the subsequent cooling. To support this hypothesis, we acquired mechanical loss spectra during a sequence of heating-cooling cycles aimed at detecting the temperatures of appearance and disappearance $\mathrm{P} 2$. At first, annealing periods $(30 \mathrm{~min}$. $)$ at $950^{\circ} \mathrm{C}$, which ensure dissolution of "B" precipitates, were followed by cooling at gradually decreasing temperatures ramps of $50^{\circ} \mathrm{C}$. The criterion for establishing the precipitation temperature was the disappearance of the peak P2 upon heating. The peak P2 disappears if the cooling temperature falls below $700^{\circ} \mathrm{C}$. This places the precipitation temperature close to $700^{\circ} \mathrm{C}$, in good agreement with TEP observations.

In a second experiment, we performed heating and cooling cycles starting from $550^{\circ} \mathrm{C}$ and gradually increasing the final annealing temperature. This allowed identifying the dissolution temperature with the temperature needed for the appearance of the peak P2 on cooling, i.e. the annealing temperature necessary to observe the hysteresis with the cooling. IF curves upon cooling do not show the peak P2 for annealing at a temperature below $850^{\circ} \mathrm{C}$. Therefore, the dissolution temperature of "B" precipitates should occur above $850^{\circ} \mathrm{C}$.

\section{Conclusions}

In this work, we studied the anelastic behavior of two grades of a Co-Ni-Cr based alloy, differing by the presence of a small quantity of beryllium in one of them. Mechanical spectroscopy measurements, supported by complementary techniques as thermoelectric power and transmission electron microscopy, lead to the following conclusions:

1. On cold-worked samples, recrystallization temperature occurs close to $850^{\circ} \mathrm{C}$ for the alloy "without" Be. Beryllium increases the recrystallization temperature of about $60^{\circ} \mathrm{C}$.

2. Diffusion of atoms involved in precipitation $\mathrm{A}$ provides a relaxation peak (P1) detectable on internal friction spectra at $600^{\circ} \mathrm{C}$. The activation energy of $\mathrm{P} 1$ confirms an implication of nickel and titanium atoms in the formation of "A" precipitates.

3. A second relaxation peak P2 occurring close to $800^{\circ} \mathrm{C}$ on $\mathrm{CW}$ samples is assigned to twin boundaries migration. However, solely in the beryllium-containing alloy, this peak shows a hysteretic behavior due to the presence of NiBe intermetallic compound ("B" precipitates) segregated on the twin boundaries. Dissolution of "B" precipitates $\left(\sim 900^{\circ} \mathrm{C}\right)$ allows the relaxation mechanism to occur, leading to the appearance of $\mathrm{P} 2$ during cooling.

Consistently with all our experimental results, we can affirm that beryllium strongly influence the anelastic behavior of the material, mainly by forming NiBe precipitates modifying the twin boundary motion. Thus, in addition to producing structural hardening by solid solution, beryllium seems to act on the mobility of grain boundaries, increasing the recrystallization temperature.

\section{Acknowledgments}

The authors acknowledge Dr. Thomas La Grange from the Centre Interdisciplinaire de Microscopie Électronique (CIME) at École Polytechnique Fédérale de Lausanne for the electron microscopy support.

\section{References}

1. Davis JR, ed. ASM Specialty Handbook: Nickel, Cobalt, and Their Alloys. Materials Park: ASM International; 2000.

2. Hermawan H, Ramdan D, Djuansjah JRP. Metals for Biomedical Applications. In: Fazel-Rezai R, ed. Biomedical Engineering - From Theory to Applications. Rijeka: InTech; 2011.

3. Bezzon OL, de Mattos MGC, Ribeiro RF, Rollo JMA. Effect of beryllium on the castability and resistance of ceramometal bonds in nickel-chromium alloys. The Journal of Prosthetic Dentistry. 1998;80(5):570-574.

4. Bezzon OL, Ribeiro RF, Rollo JM, Crosara S. Castability and resistance of ceramometal bonding in $\mathrm{Ni}-\mathrm{Cr}$ and $\mathrm{Ni}-\mathrm{Cr}-\mathrm{Be}$ alloys. The Journal of Prosthetic Dentistry. 2001;85(3):299304.

5. Alkmin LB, da Silva AAAP, Nunes CA, dos Santos C, Coelho GC. Microstructural evidence of beryllium in commercial dental Ni-Cr alloys. Materials Research. 2014;17(3):627-631.

6. Cosimati R, Mari D. Effects of Precipitation Hardening in Co-Ni-Cr Alloy on Dissipative Motion of Dislocations by Amplitude-Dependent Internal Friction Measurements. Archives of Metallurgy and Materials. 2015;60(4):30773082 .

7. Cosimati R, Mari D. Secondary hardening in Co-Ni-Cr superalloy investigated by Mechanical Spectroscopy. Materials Science and Engineering: A. 2016;662:426-431.

8. LaGrange T, Cosimati R, Lazar S, Mari D. Characterization of the $\mathrm{NiBe}$ nanoprecipitates in $\mathrm{CoCr}$ superalloys. In: Proceedings of European Microscopy Congress 2016; 2016 Aug 28-Sep 2; Lyon, France.

9. Feng ZH, Jiang XJ, Zhou YK, Xia CQ, Liang SX, Jing R, et al. Influence of beryllium addition on the microstructural evolution and mechanical properties of $\mathrm{Zr}$ alloys. Materials \& Design (1980-2015). 2015;65:890-895.

10. Nowick AS, Berry BS. Anelastic Relaxation in Crystalline Solids. New York: Academic Press; 1972.

11. Schaller R, Fantozzi G, Gremaud G, eds. Mechanical Spectroscopy $\mathrm{Q}^{-1}$. Materials Science Forum. 2001;366-368.

12. Blanter MS, Golovin IS, Neuhäuser H, Sinning HR. Internal Friction in Metallic Materials: A Handbook. Berlin Heidelberg: Springer-Verlag; 2007.

13. Cosimati R. Évolution microstructurale et propriétés mécaniques d'un alliage Co-Ni-Cr. Thesis. Lausanne: École Polytechnique Fédérale de Lausanne; 2016.

14. Maier A, Tkalcec I, Mari D, Schaller R. Grain boundary formation stages in a deformed yellow gold single crystal studied by mechanical spectroscopy. Materials Science and Engineering: A. 2013;560:466-472. 
15. Maier AK, Mari D, Tkalcec I, Schaller R. Grain boundary relaxation in yellow gold bi-crystals. Materials Science and Engineering: A. 2015;632:43-49.

16. R. Schaller. Applications of mechanical spectroscopy to industrial materials. Archives of Metallurgy and Materials. 2015;60:1085-1089.

17. Schoeck G, Bisogni E, Shyne J. The activation energy of high temperature internal friction. Acta Metallurgica. 1964;12(12):14661468 .

18. Benoit W. 4.2 Grain Boundary Relaxations in Metals. Materials Science Forum. 2001;366-368:306-314.

19. Pelletier JM, Vigier G, Mai C, Borrelly R. Influence of the initial stages of precipitation on the electrical properties of Cu-Be Alloys. Acta Metallurgica. 1983;31(10):1491-1496.
20. Benkirat D, Merle P, Borrelly R. Effects of precipitation on the thermoelectric power of iron-carbon alloys. Acta Metallurgica. 1988;36(3):613-620.

21. Massardier V, Lavaire N, Soler M, Merlin J. Comparison of the evaluation of the carbon content in solid solution in extra-mild steels by thermoelectric power and by internal friction. Scripta Materialia. 2004;50(12):1435-1439.

22. Maier AK, Tkalcec I, Mari D, Schaller R. Recrystallization and Grain Boundary Formation in an 18-Carat Gold Alloy Studied by Mechanical Spectroscopy. Materials Science Forum. 2013;753:17-20.

23. Le Claire A. Difusion in Metals. In: Brandes E, ed. Smithells Metals Reference Book. $6^{\text {th }}$ ed. Oxford: Butterworth; 2004. p. 13.1-13.97. 